International Journal on Cybernetics \& Informatics (IJCI) Vol. 5, No. 4, August 2016

\title{
A Design of Double Swastika Slot Micro- STRIP ANTENNA FOR ULTRA WIDE BAND AND WIMAX APPLICATIONS
}

\author{
G. Rama Krishna, Dr. N.Venkateswara Rao G. Anil Kumar \\ Associate Professor, Aditya College of Engineering, Surampalem \\ Professor, Bapatla Engineering College , Bapatla \\ Assistant Professor, Anurag group of Institutions, Hyderabad
}

\begin{abstract}
This paper presents a design of double Swastika Slot Micro-strip Antenna which can be used in UWB and WiMAX Applications. The proposed antenna operates at resonant frequencies $3 \mathrm{GHz}$ and $3.11 \mathrm{GHz}$. At $3 \mathrm{GHz}$ obtained value of VSWR is 1 and return loss is $-42 \mathrm{~dB}$ and at $3.11 \mathrm{GHz}$ VSWR is 1.7 and return loss is -12dB. RT Duroid having dielectric constant 2.2 is used as substrate. Here the double Swastika slot Antenna is fed with the coaxial feeding technique.
\end{abstract}

\section{KEYWORDS}

VSWR, Return loss, Double Swastika slot antenna.

\section{INTRODUCTION}

Circularly Polarized Micro-strip antennas are widely employed in UWB, WiMAX, RADAR, mobile Communication, aircraft, spacecraft, satellite communication and RFID applications where small size i.e. portability, low cost, high performance, ease of installation, low power consumption and the capability to transmit information at high data rates are major constraints. Liability to transmit and receive maximum power is influenced by polarization of the antenna. UWB is a promising technology for many real time applications as this technology consumes very low power and WiMAX technology provides portable mobile broadband connectivity across nations through a variety of devices. A Compact design of double slotted swastika antenna for circular polarization is proposed and introduced. Circular polarization is brought about by Embedding micro Swastika slot with in main Swastika slot. Since RT Duroid offers better radiation it is selected as a substrate. It offers many advantages such as lowest dielectric loss, low moisture absorption, uniform electrical properties over entire frequency range, high thermal Resistance and conductivity, excellent characteristics for High frequency and excellent high speed and functionality for portable electronic devices in rapidly expanding mobile network. Major limitations of Micro-strip antenna are its narrow Bandwidth and Gain .The design of 
portable antenna configuration further deteriorates the two parameters, which is the most serious disadvantage preventing it from being used in microwave applications.

Therefore portability, along with Gain and BW enhancement is becoming major design considerations for real time applications of Micro-strip antenna for wireless communication. Here we are proposing an innovative technique to enhance gain and BW of Micro-strip patch antenna. Slots are cut into double swastika shape to improve the BW and also satisfies convenient impedance matching over entire broad frequency of operation. Characteristics such as dual and circular polarization, dual frequency operation, broad bandwidth, feed line flexibility and so on are easily obtained in this patch shape. Patch is excited by coaxial feed in this particular design. Simulation and Experimental results of antenna are prescribed and discussed here.

\section{ANTENNA DESIGN \& CONFIGURATION}

Slots are cut in the design such that they appear in the shape of Double Swastika slot antenna. The Inner Swastika slots are extended from main Swastika slots and the legs of Inner swastika slots are smaller than the legs of the main Swastika slots. The shape of double Swastika slots could provide desired Band width because of variations in the current distribution and the radiation pattern at the edges. Patch width is properly adjusted to get improved results.



Fig.1 Double swastika slot 


\section{Design Equations:}

$$
\begin{aligned}
& \Delta L=0.412 h \frac{\left(\varepsilon_{\text {reff }}+0.3\right)\left(\frac{W}{h}+0.264\right)}{\left(\varepsilon_{\text {reff }}-0.258\right)\left(\frac{W}{h}+0.8\right)} \\
& W=\frac{c}{2 f_{o} \sqrt{\frac{\left(\varepsilon_{r}+1\right)}{2}}} \\
& L_{e f f}=\frac{c}{2 f_{o} \sqrt{\varepsilon_{r e f f}}} \\
& \varepsilon_{r e f f}=\frac{\varepsilon_{r}+1}{2}+\frac{\varepsilon_{r}-1}{2}\left[1+12 \frac{h}{W}\right]^{-\frac{1}{2}}
\end{aligned}
$$

Where,

$\Delta \mathrm{L}=$ increased length due to fringing effect

$\mathrm{W}=$ Patch width of the antenna

$\mathrm{L}_{\mathrm{eff}}=$ Effective length of the patch

$\varepsilon_{\text {eff }}=$ Effective dielectric constant of the substrate

$\mathrm{C}=$ Speed of light

$\mathrm{h}=$ height of the substrate

$\mathrm{f}_{0}=$ Resonant frequency 


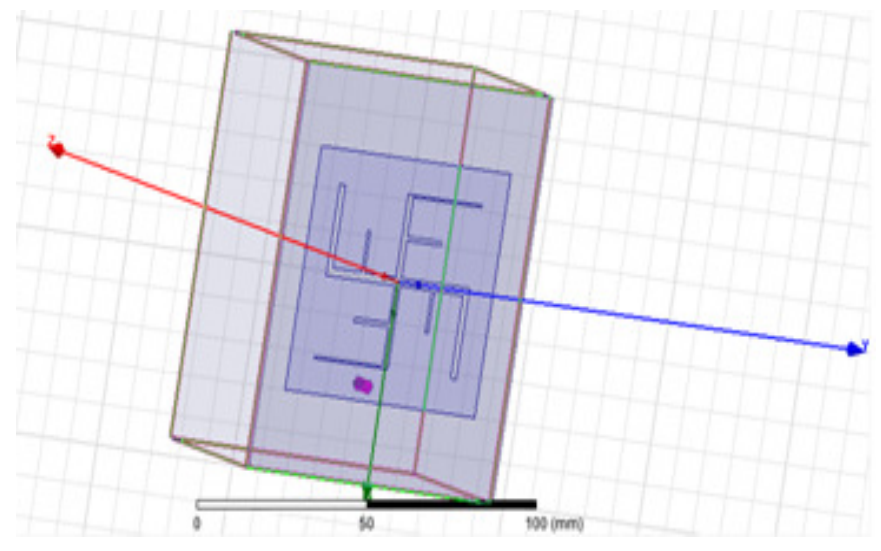

Fig. 2 The construction view of double swastika slot antenna with feed

Micro-strip antenna in general can be fed from underneath via a probe as shown in the above figure. The outer conductor of the cable is connected to the ground plane, the center conductor is extended up to reach the patch antenna and the antenna efficiency in terms of return loss mainly depend up on the impedance matching between patch and transmission feed line. We get more efficient results when both transmission feed and patch have perfect impedance matching.

The position of the feed can be altered to control the input impedance. The coaxial feed introduces an inductance in to the feed point that may need to be taken into account if the height $h$ gets large i.e. an appreciable fraction of wavelength. In addition the probe will also radiate, which can lead to radiation in undesirable conditions. The main aim to use coaxial or probe feeding is that, it enhances the gain, provides narrow bandwidth and perfect impedance matching.



Fig.3 Top view of Double Swastika Slot Patch Antenna

Feed point is varied to different positions to get good radiation and impedance matching. While cutting the slot optimum dimensions should be considered. So the dimensions of slot are important for good efficiency of antenna. 


\section{THE DESIGNING PARAMETERS}

\begin{tabular}{|c|c|}
\hline Length of the patch(Lp) & $60 \mathrm{~mm}$ \\
\hline Width of the patch(Wp) & $70 \mathrm{~mm}$ \\
\hline Height of the substrate(Hs) & $1.6 \mathrm{~mm}$ \\
\hline $\begin{array}{c}\text { Length of the substrate(Ls) } \\
\text { Width of the substrate (Ws) }\end{array}$ & $100 \mathrm{~mm}$ \\
\hline $\begin{array}{c}\text { Outer cylinder Radius } \\
\text { (Rout) }\end{array}$ & $1.6 \mathrm{~mm}$ \\
\hline $\begin{array}{l}\text { Inner cylinder Radius (Rin) } \\
\text { Height of the air box (Ha) }\end{array}$ & $0.7 \mathrm{~mm}$ \\
\hline
\end{tabular}

Correct position of substrate, ground and patch can be obtained by properly using the following equations. Ten rectangular boxes (gaps) are required to get the shape of double swastika slot patch antenna. Slot sizes can be varied using the following equations.

1. Substrate $-\mathrm{Ls} / 2, \mathrm{Ws} / 2,0 \mathrm{~mm}$

2. Ground - Lp/2,Wp/2,-h

3. Patch $-\mathrm{Lp} / 2, \mathrm{Wp} / 2,, 0 \mathrm{~mm}$

4. Gap1 -lp/2-(c+e), -d/2,0mm

5. Gap2--d/2,-k/2,0mm

6. Gap3 -lp/2-e ,k/2,0mm

7. Gap4 -(lp/2-e)-a ,-k/2,0mm

8. Gap5 --lp/2+e ,-k/2,0mm

9. Gap6 -lp/2+e , $\mathrm{k} / 2,0 \mathrm{~mm}$

10. Gap7 $-((\mathrm{c} / 2)+(\mathrm{d} / 2)) / 2, \mathrm{~m} / 2+\mathrm{d} / 2,0 \mathrm{~mm}$

11. Gap8 $-((\mathrm{c} / 2)+(\mathrm{d} / 2)) / 2,(\mathrm{~m}-\mathrm{k} / 2), 0 \mathrm{~mm}$

12. Gap9- $((\mathrm{c} / 2)+(\mathrm{d} / 2)) / 2,-((\mathrm{k} / 2)+(\mathrm{d} / 2)) / 2,0 \mathrm{~mm}$

13. Gap10 $-((\mathrm{c} / 2)+(\mathrm{d} / 2)) / 2, \mathrm{k} / 4+\mathrm{d} / 4,0 \mathrm{~mm}$ 
14. Air box-((c/2)+(d/2))/2, $\mathrm{k} / 4+\mathrm{d} / 4,0 \mathrm{~mm}$

Where

$\mathrm{C}=\mathrm{lp}-(2 * \operatorname{lp} / 7)$

$\mathrm{k}=\mathrm{wp}-(2 *(\mathrm{wp} / 8))$

$\mathrm{e}=(\mathrm{lp}-\mathrm{c}) / 2$

$\mathrm{m}=(\mathrm{k} / 2)-\mathrm{d} / 2$

\section{RESULTS \& DISCUSSION}

In the design, dual band frequency characteristics are obtained and the analysis using HFSS simulation tool resulted in acceptable values for Return Loss, VSWR and Gain.

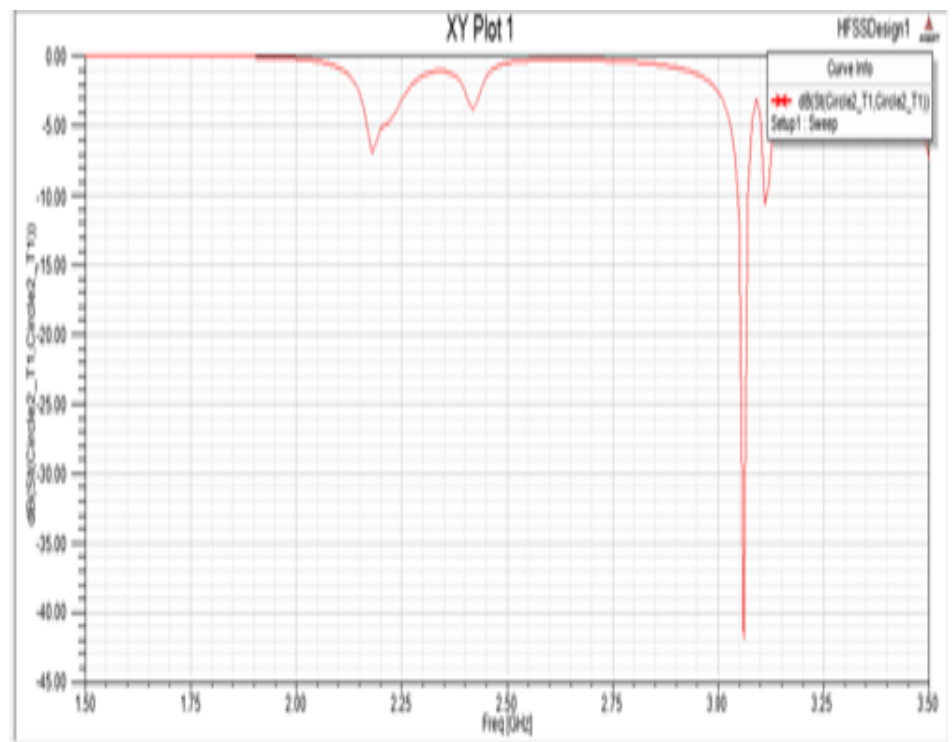

Fig.4 Return loss at two proposed frequencies $(3 \& 3.11 \mathrm{GHz})$ 
International Journal on Cybernetics \& Informatics (IJCI) Vol. 5, No. 4, August 2016

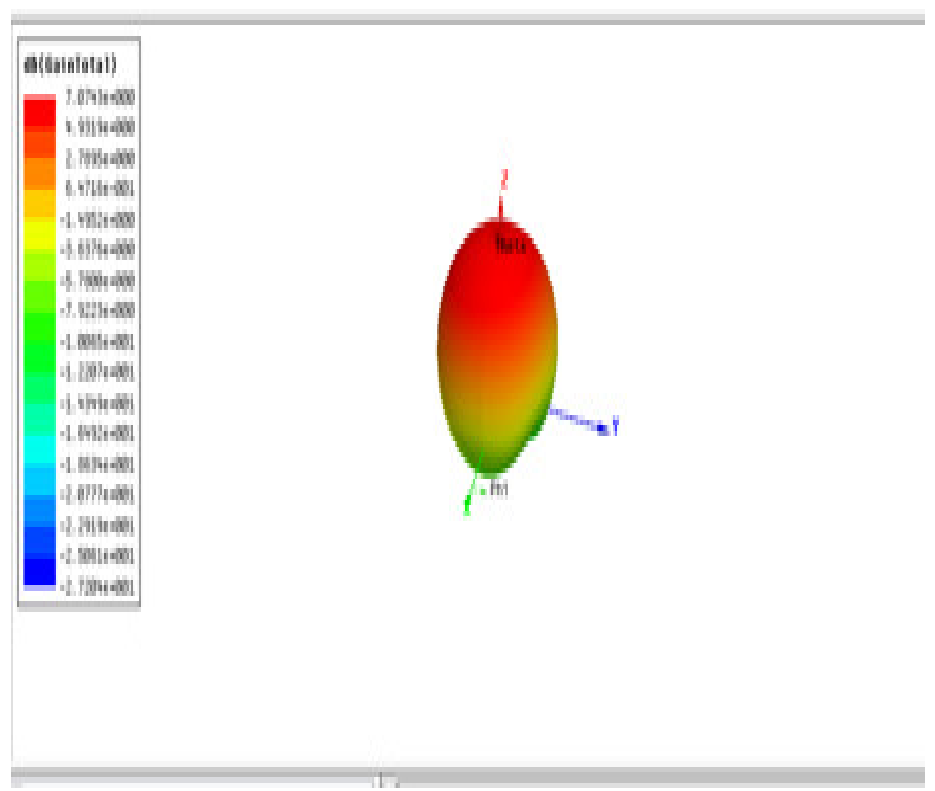

Fig.5 Gain plot of the Double swastika slot microstrip patch antenna

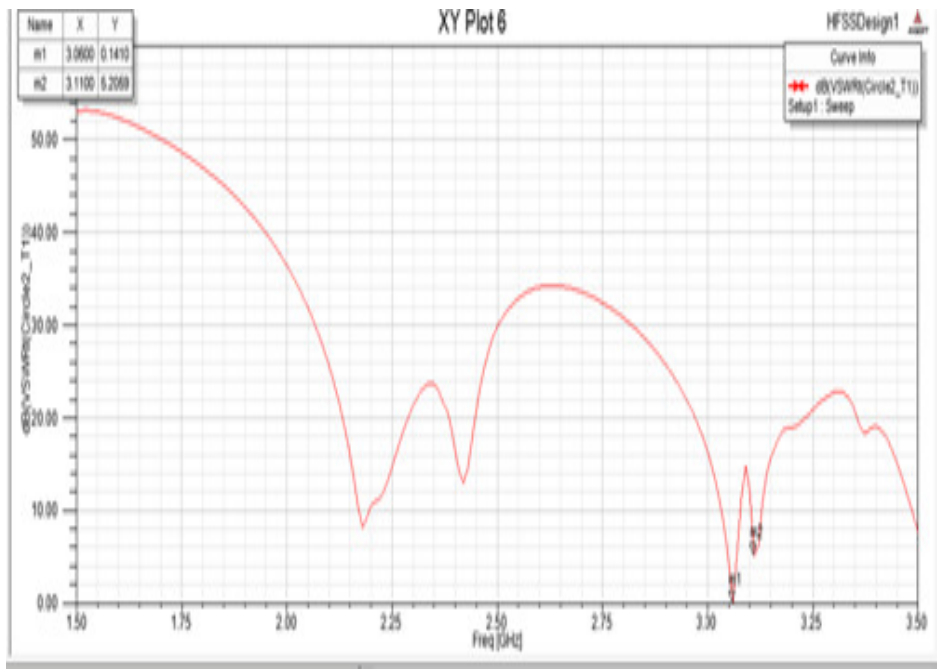

Fig.6 VSWR at two proposed frequencies $(3 \& 3.11 \mathrm{GHz})$

Above results shows that Return loss and VSWR as
At $3 \mathrm{GHz}$, Return loss
$=-40 \mathrm{~dB}$
VSWR
$=1$
At $3.11 \mathrm{GHz}$, Return loss
$=-12 \mathrm{~dB}$ 
International Journal on Cybernetics \& Informatics (IJCI) Vol. 5, No. 4, August 2016

VSWR $\quad=1.7$

Hence VSWR $(<2)$ and Return loss $(<-10 \mathrm{~dB})$ obtained in the acceptable range.

\section{CONCLUSION}

A double Swastika slot patch antenna with coaxial feed line was designed and simulated here. The values of Return loss and VSWR were accomplished in the acceptable range. VSWR 1 and 1.7, Return loss $-42 \mathrm{~dB}$ and $-12 \mathrm{~dB}$ were achieved at resonant frequencies $3 \mathrm{GHz}$ and $3.11 \mathrm{GHz}$ respectively. Gain of about $7 \mathrm{~dB}$ achieved. Slot dimensions were varied to get desired results. The proposed Antenna in this paper can be used in UWB and WiMAX Applications. Here HFSS Simulation tool has been used.

\section{REFERENCES}

[1] Prakash Kumar Mishra, Vidhi Sachdeva, Drishti Sharma, A Swastika slot Micro-Strip Antenna for 3G Mobile Applications

[2] Vivek Singh Rathor, Jai Prakash Saini, A design of Swastika Shaped Wideband Micro-Strip Patch Antenna for GSM/WLAN Applications

[3] Latif, S.I, Sharif \& Sharma,S.K." Bandwidth enhancement and size reduction of Micro-strip patch antenna “,IEEE Transactions on Antenna and propagation,53(3),994-1003,2005

[4] D.R. Tanner,Y.T.Lo,"Analysis of rectangular Micro-strip antenna excited by a slot line”, National Radio Science Meet[URSI] January 1988

[5] D.Caratelli,R.Cicchetti,G.Bit-Babik and A.Faraone,"A purbuted E-shaped Patch antenna for wideband WLAN applications", IEEE Transactions on antenna propagate, Vol 54.,No.6,pp 18711874,2006 